\title{
GCU
}

Glasgow Caledonian

University

University for the Common Good

\section{Systems engineering approach to design and modelling of smart cities}

Muvuna, Jules; Boutaleb, Tuleen; Mickovski, Slobodan; Baker, Keith

Published in:

2016 International Conference for Students on Applied Engineering, ICSAE 2016

DOI:

10.1109/ICSAE.2016.7810231

Publication date:

2017

Document Version

Author accepted manuscript

Link to publication in ResearchOnline

Citation for published version (Harvard):

Muvuna, J, Boutaleb, T, Mickovski, S \& Baker, K 2017, Systems engineering approach to design and modelling of smart cities. in 2016 International Conference for Students on Applied Engineering, ICSAE 2016. IEEE, pp. 437-440, International Conference for Students on Applied Engineering (ICSAE), 20/10/16. https://doi.org/10.1109/ICSAE.2016.7810231

\section{General rights}

Copyright and moral rights for the publications made accessible in the public portal are retained by the authors and/or other copyright owners and it is a condition of accessing publications that users recognise and abide by the legal requirements associated with these rights.

Take down policy

If you believe that this document breaches copyright please view our takedown policy at https://edshare.gcu.ac.uk/id/eprint/5179 for details of how to contact us. 


\title{
Systems Engineering Approach to Design and Modelling of Smart Cities
}

\author{
J. Muvuna*, T. Boutaleb*, S.B. Mickovski * and K.J. Baker* \\ * School of Engineering and Built Environment, Email: Jules.Muvuna@gcu.ac.uk \\ Glasgow Caledonian University \\ United Kingdom.
}

\begin{abstract}
A city is a very complex area with complex governing bodies and a number of decision makers. More often, cities are engines of economic development and are attractive places for people seeking employment and better quality of living [1]. As a consequence, cities are now facing a growing urban population which imposes stresses on urban quality of life and the environment. Among the major challenges faced by cities around the world, urban population growth is at the forefront as it is expected that future cities will be home for more than $70 \%$ of the global population by 2050 . Other associated challenges include traffic congestion, environmental degradation, security, level of quality of public services, and effective resources management. To ensure sustainable development of cities with such a boom of urbanisation, cities around the world are embracing technology and adopting smart cities concept following the recorded development of information and communication technologies and internet of things. However, the literature [2] shows that the concept of smart cities is not being approached efficiently. A smart city is a system of subsystems and should be approached as a whole as opposed to infusing technology into subsystems one by one. To achieve this, there is a requirement of a standard platform to integrate all the subsystems of a smart city system. This work proposes a holistic model which integrates all the subsystems of a smart city system. The proposed model is based on systems engineering approach and Systems Engineering Modelling Language (SysML) is adapted as a potential modelling language. It is a general purpose visual modelling language for Systems Engineering applications and for complex systems such as smart cities and can handle better complexity and challenges such as documentation, communication, and management.
\end{abstract}

Index Terms-Smart City System, Systems Engineering, Systems Modelling Language (SysML)

\section{INTRODUCTION}

The registered considerable increase of global population in general and urban population in particular have been challenging cities and governments with regards to how to combine sustainable development with the escalating urban population. It can be argued that among the major causes of these challenges, the urban population growth is at the forefront [3] [4]. It is expected that future cities will be home of more than $70 \%$ of the global population by 2050 [5] [6]. Increase of urban population means that more people will need public services, more cars will be on urban road networks, more parking space will be required, more people will need health services in urban areas, more educational institutions will be on demand, etc. All these come as threats to sustainable urban development and make the existing complexity of cities' management even more complex. The forever growing urban population has been the driving force of the smart cities concept popularity and the concepts has caught attention of a very large number of cities and governments around the world. It is believed that smart cities concept is the most efficient and cost effective way of delivering services faster and efficiently and can improve the environment and daily activities of people living in urban environment [7]. Over the last decades, smart cities concept and its ability to allow sustainable development and improve quality of life have spread and cities around the world have been working with the aim of becoming smart cities. There are two approaches which are used by cities in the process of becoming smart cities; The first approach is the transformation of existing cities into smart cities by infusing technology into existing infrastructures to allow smart operations. This is the case of cities such as Barcelona, Santander, Seoul, etc. The second approach is building a smart city from scratch, which is the case of Masdar City in Abu Dhabi in the United Arab Emirates which aimed to be the first city in the world to become zero carbon city and PlanIT Valley in Portugal.

Future cities will rely on technologies to support better offering of public services and dealing with many more other challenges faced in urban environment. A number of cities are now given a label of smart cities through transformation of either one subsystems of a city system by making it operate intelligently or by improving public services delivery using technology, etc. [8]. However, a city is a system of systems which means that transformation of a city into smart city is a transformation of a system into smart system. This shows that the approach of transformation into smart city should consider a city as a whole and a city to be labelled as a smart city should have all the subsystem of a city operating in a smart way and together as an integrated smart city system. However, the literature shows that most of the cities which are now considered as smart cities are yet to be smart as infusing technology or intelligence in one subsystem of a city system does not make a city smart [8] [2]. Therefore such an approach of transformation is not considered as a smart way of transformation [9] as it jeopardises the target of achieving a targeted integrated system. Only some of the subsystems would be operating intelligently, not the entire city system. Therefore, what makes a city smart is not having some of the subsystems transformed into smart, rather it is being able to transform the city system as a whole and being able to integrate all the subsystems of a city system and making them operate in an integrated manner on a standard platform, intel- 
ligently sharing information which would ultimately improve quality of life of citizens and would allow them to efficiently use resources by taking informed decision in daily activities. The lack of such crucial standard platform motivates this research and creates a need of a model for such a complex platform. Until now, published research proposes architectures, methods and approaches that could allow transformation of conventional cities into smart cities by considering one subsystem of interest in a city but has not been able to provide a model of an integrated smart system in which all smart subsystems operates in an integrated manner sharing information which would benefit citizens and decision makers as it would give them access to information in real time and the possibility to make informed decisions through easy and free accessible information. This work proposes a model of such a standard platform as a starting point which will permit to understand how to better approach city transformation to achieve an integrated smart city system.

\section{CONCEPTUALISING A SMART CITY SYSTEM}

The literature shows that researchers define the smart cities concept stressing on technology [10] [7] and considering it either as a system with subsystems which make it a system of systems [8] or as a city with different smart dimensions [11], or again as a city with different domains [7]. IBM defined a smart city as one that integrates key information of core systems [12].Giffinger and Pichler-Milanović [13] and Giffinger and Gudrun [14] mentioned that a city to be considered as smart has to perform very well in six characteristics: mobility, environment, living, economy, governance, and people. These six characteristics have been validated by a number of researchers [15] [16] [17] [18]. The six identified characteristics together constitute a city system and the transformation of a city system should begin with transformation of the six characteristics, which can be considered as subsystem of a city system. Hence, the process of transformation of a city into smart city system constitutes of transformation of all the six subsystems into smart subsystem in an integrated manner rather than focusing on transformation of one subsystem. The six identified subsystems are described in the following paragraph based on the research by Giffinger and PichlerMilanović [13].

1. Smart economy: it should be one that allows optimisation of resources usage, develops policies that allow economic development, the one that is sustainable and create jobs which are accessible to all, stop losses of jobs and address unemployment. Smart economy is able to enhance the quality of life in a city, attract and accommodate tourists and is the engine of the city.

2. Smart mobility: smart mobility generally involves efficient transportation systems which make use of time and energy efficiently. It also involves transportation systems which use renewable energy rather than relying on fossil fuel and encourage and promote non-motorised transportation.

3. Smart living: It provides the ability to maintain or improve the quality of public services delivered to cities inhabitants and provides a possibility to improve the quality of living conditions. The success of smart living depends on living conditions which are healthy and inclusive.

4. Smart people: smart cities are enabled by a various enabling technologies. Therefore, people will need to have a certain level of skills, qualification, creativity, and willingness to adapt to new technologies and other intelligent way of doing thing to transform their cities. The success of smart people will be determined by having skilled and educated citizens who have the willingness to participate in decision making process and present their opinion with regards with the development.

5. Smart environment: smart environment means cutting down emission, good management of natural resources, preservation of the nature, and finding innovative solution to any other threats that come to degrade the environment. The succeed of smart environment requires an urban development plan and good policies for resources management.

6. Smart governance: governance of a city should be seen as being able to manage a city to allow sustainable urban development. A smart government is described as one which is transparent, which develops strategies in line with sustainable development, and one which has efficient and interconnected governance.

\section{PROPOSED MODEL OF A SMART CITY SYSTEM}

As discussed above, a smart city is a smart system of smart subsystems and the transformation of a city system into smart city system is a transformation of a system and needs to be transformed as a system. To advance the knowledge of city systems transformation, this work proposes a transformation approach. The proposed approach considers a city as a system and one whole entity, presents a model in which a smart city function as a smart system and shows how smart subsystems of a city system gather data from different sources, process it, and share information on an integrated platform.

\section{A. Methodology}

To achieve the transformation of the system mentioned above, systems engineering approached is used. It is an interdisciplinary approach, allows the realisation of a successful system and is a good fit for design of complex system such as a city system. The approach is complemented by Systems Modelling Language (SysML). It is a general purpose modelling language which uses graphics to support specification, analysis, design, verification, and validation of complex systems. It also allows representing systems architectures, their functionalities and behaviour and it is capable of handling better complex systems documentation related issues [19].

\section{B. The model of a smart city system}

The structure of the proposed holistic model of a smart city system is illustrated on Figure 1 where the identified six smart subsystem are presented. On the presented structure, all the subsystems of a smart city are brought together on an integrated platform. The structure shows that all the smart subsystems are connected through a standard platform which integrates them and makes them operate together as 


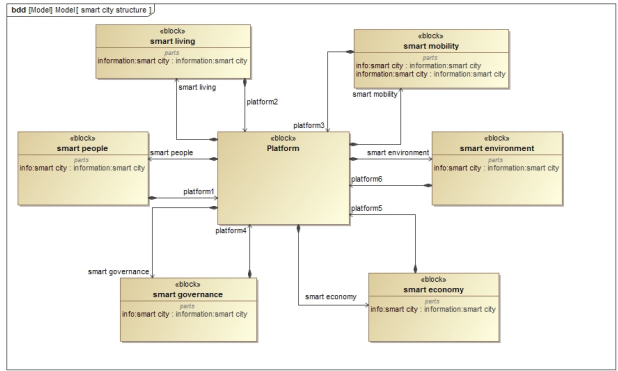

Fig. 1: The structure of the proposed smart city system.

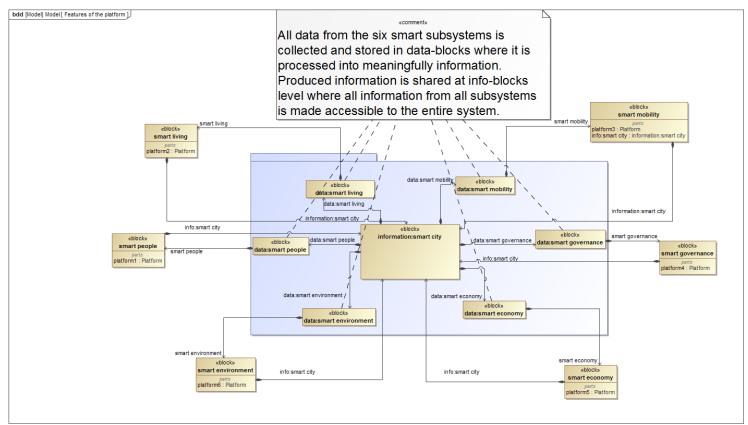

Fig. 2: The smart city platform operation structure.

connected parts of smart city systems. The operations at the platform level are illustrated on Figure 2. The figure presents the smart subsystems as parts of a smart system in which data blocks source data from smart subsystems and process it into meaningful information which can easily be understood by the users.

Operations on Figure 2 can be explained into three stages: Data production stage: In this first stage, the smart subsystems of a city system operates only producing data. There are six smart subsystems (see section) in which sources of information produce data to be stored into the data block. Each smart subsystem stores its data into its respective data block. This means that there are as many data blocks as there are smart subsystems. Sources of information in which data is produced can be sensors, any smart gadget, etc. - Data processing: Data produced by different sources of information from different smart subsystems is stored in data

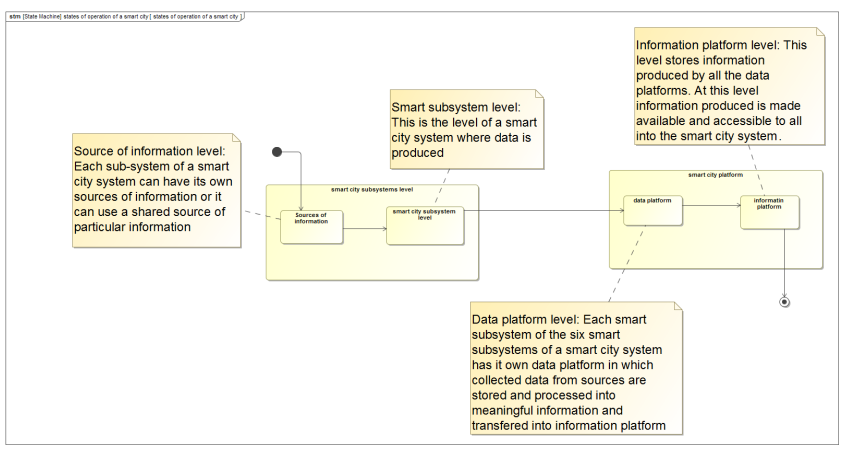

Fig. 3: Illustration of operation of the model of a smart city system. platform and it is at this level where meaningful information is produced. The processing of data at the data block level produces information which is stored at the information block level. - Sharing of information: Information produced from processing data at the data block level is stored at the information block level. It is from there that information is made available to all and everybody in the smart city system have access to information.

To understand the operation of the presented model, a state machine diagram is presented on Figure 3. The diagram shows states of an executed diagram in which the smart system of a city goes through in its operations as presented by the structure of the model on Figure 1. Sources of data will be the starting point through which data is produced by a number of means such as sensors, smart phone, etc. Data will then be sourced and stored at the level of data block, and it is at this level where it will be processed into meaningful information which will be stored into information platform. As it can be seen on Figure 1, every single smart subsystem sources its own data which it processes to produce information, and transfers it to the information block. Data block and information block operate at the platform level as it can be seen on Figure 2 .

\section{Discussion}

Future smart cities potential is huge and cities around the world are in the process of transformation into smart cites. However, the success of such transformation depends on how it is done. A city is a system which means that it needs to be approached as a system and transformed as a system. Transformation of a city system into smart city system consists of infusing technology into existing city infrastructures to allow smart operations. Drawing on the reviewed literature on smart city, we proposed an integrated model with a standard platform which presents a transformed city system into smart city system and shows how the flow of information can be done as opposed to transformation of subsystems of a city system one by one which is considered as not the best practice and could lead to a segmented city system. For sustainable design of a city system, one must provide a holistic model to allow functional quality, technical quality, and processing quality of a smart city system. An integrated structure of a model of a smart city system is presented and gives a visual representation of how a transformed city system into smart city system operates. The model presents an integrated platform on which information is shared and made available to both citizens and decision makers. Having such a model gives a visual representation of a smart city system and how a transformed smart city could operate.

\section{A. Benefits of having the model}

It is essential to ensure high quality of life for cities inhabitants in a healthy and safe environment through next generation smart cities. Presented smart cities system model will benefits citizens as it will give them access to information in real time and the possibility to make informed decisions through easy and free access to information. It is very convenient to 
have all the information together on a standard information platform and it makes it easier for users as they do not have to spend time looking for different information on different platforms. It also gives the possibility to decision makers to make informed decision and allow them to develop policies having good understanding of what impact it would have on the entire city system.

Financially, It is very difficult at this stage to quantify exactly benefits of having such an integrated system, but it is definite that access to information can for example allow traveller to decide which would be the most economical mode of transport at a particular point in time. To have a clearer view, future work will address this matter.

\section{FUTURE WORK}

The model presented here illustrates how an integrated platform of a smart city system can be modelled. However, the model only presents an initial step of a large project and the main objective of the project is to generate a detailed model of such a standard platform and to give a visual semantic representation of different modelling stages. This will permit to understand better how to proceed with cities transformation into smart cities which gives an integrated smart system as a result. Therefore, future work will consist of developing the model in a more detailed manner to have a full model which shows full functionality.

\section{REFERENCES}

[1] R. Barna and D. Reianu, "Cities; between engines for growth, and development," Studia Universitatis Babes-Bolyai. Studia Europaea, vol. 58, no. 3, p. 19, 2013.

[2] R. Moss Kanter and S. S. Litow, "Informed and interconnected: A manifesto for smarter cities," Harvard Business School General Management Unit Working Paper, no. 09-141, 2009.

[3] M. Asif and T. Muneer, "Energy supply, its demand and security issues for developed and emerging economies," Renewable and Sustainable Energy Reviews, vol. 11, no. 7, pp. 1388-1413, 2007.

[4] B. Liddle, "Impact of population, age structure, and urbanization on carbon emissions/energy consumption: evidence from macro-level, crosscountry analyses," Population and Environment, vol. 35, no. 3, pp. 286 304, 2014.

[5] I. Cianci, G. Piro, L. A. Grieco, G. Boggia, and P. Camarda, "Content centric services in smart cities," in 2012 Sixth International Conference on Next Generation Mobile Applications, Services and Technologies. IEEE, 2012, pp. 187-192.

[6] P. C. Annez and R. M. Buckley, "Urbanization and growth: Setting the context," Urbanization and growth, vol. 1, pp. 1-45, 2009.

[7] C. Yin, Z. Xiong, H. Chen, J. Wang, D. Cooper, and B. David, "A literature survey on smart cities," Science China Information Sciences, vol. 58 , no. 10 , pp. $1-18,2015$.

[8] T. Nam and T. A. Pardo, "Conceptualizing smart city with dimensions of technology, people, and institutions," in Proceedings of the 12th Annual International Digital Government Research Conference: Digital Government Innovation in Challenging Times. ACM, 2011, pp. 282291.

[9] J. Gubbi, R. Buyya, S. Marusic, and M. Palaniswami, "Internet of things (iot): A vision, architectural elements, and future directions," Future Generation Computer Systems, vol. 29, no. 7, pp. 1645-1660, 2013.

[10] G. C. Lazaroiu and M. Roscia, "Definition methodology for the smart cities model," Energy, vol. 47, no. 1, pp. 326-332, 2012.

[11] V. Albino, U. Berardi, and R. M. Dangelico, "Smart cities: Definitions, dimensions, performance, and initiatives," Journal of Urban Technology, vol. 22, no. 1, pp. 3-21, 2015.

[12] C. Harrison, B. Eckman, R. Hamilton, P. Hartswick, J. Kalagnanam, J. Paraszczak, and P. Williams, "Foundations for smarter cities," IBM Journal of Research and Development, vol. 54, no. 4, pp. 1-16, 2010.
[13] R. Giffinger and N. Pichler-Milanović, Smart cities: Ranking of European medium-sized cities. Centre of Regional Science, Vienna University of Technology, 2007.

[14] R. Giffinger and H. Gudrun, "Smart cities ranking: an effective instrument for the positioning of the cities?" ACE: Architecture, City and Environment, vol. 4, no. 12, pp. 7-26, 2010.

[15] O. Přibyl and T. Horák, "Individual perception of smart city strategies," in Smart Cities Symposium Prague (SCSP), 2015. IEEE, 2015, pp. $1-6$.

[16] C. Manville, G. Cochrane, J. Cave, J. Millard, J. K. Pederson, R. K. Thaarup, A. Liebe, M. Wissner, R. Massink, and B. Kotterink, "Mapping smart cities in the eu," 2014.

[17] L.-G. Cretu, "Smart cities design using event-driven paradigm and semantic web," Informatica Economica, vol. 16, no. 4, p. 57, 2012.

[18] S. Sabri, A. Rajabifard, S. Ho, M.-R. Namazi-Rad, and C. Pettit, "Alternative planning and land administration for future smart cities [leading edge]," IEEE TEchnology and SocIETy MagazInE, vol. 34, no. 4, pp. 33-73, 2015.

[19] S. Friedenthal, A. Moore, and R. Steiner, "Integrating sysml into a systems development environment a practical guide to sysml," Elsevier, pp. 523-556, 2012. 